\title{
Welding Microstructure and Tensile Properties of S45C Carbon Steel
}

\author{
Chin-Guo Kuo, ${ }^{*}$ Jin-Chung Chang, ${ }^{2}$ Yi-Hsuan Hung, ${ }^{1}$ \\ Yen-Tien Kang, ${ }^{1}$ Chen-Yang Kao, ${ }^{3}$ and Jung-Hsuan Chen ${ }^{1 * *}$ \\ ${ }^{1}$ Department of Industrial Education, National Taiwan Normal University, \\ 162, Sec. 1, Heping E. Rd., Taipei 10610, Taiwan \\ ${ }^{2}$ Department of Mechanical Engineering, TungNan University, \\ No. 152, Sec. 3, Beishen Rd., Shenkeng Dist., New Taipei City 222, Taiwan \\ ${ }^{3}$ Institute of Materials Science and Engineering, National Taipei University of Technology, \\ 1, Sec. 3, Zhong-Xiao E. Rd., Taipei 10608, Taiwan
}

(Received November 15, 2017; accepted January 10, 2018)

Keywords: S45C carbon steel, welding, microstructure, tensile property

The purpose of this study was to investigate the dissimilar joint properties of $\mathrm{S} 45 \mathrm{C}$ carbon steel with multi-layer and multi-pass welding. We used four weld rods labelled A, B, C, and D to experimentally examine the influence on microstructures. $\mathrm{A}, \mathrm{B}$, and $\mathrm{C}$ were medium carbon steels while D was stainless steel. The microstructures of joint beads were observed with an optical microscope. The specimens for tensile tests were made in accordance with American Society for Testing and Materials (ASTM) E8M. The experimental results were as follows: (1) Pearlite structures and bainite structures were formed in the welded zone by the weld rods of medium carbon steels. The yield strength and ultimate strength of the specimens were 360 and $460 \mathrm{MPa}$, respectively. (2) The feature of welded specimen D was close to stainless steel because the stainless steel rod included some $\mathrm{Cr}$ and Ni. The yield strength and ultimate strength of specimen D showed increases of 35 and $65 \%$ compared to the other specimens. In addition, a ferritic-austenitic stainless steel, known as dual phase stainless steel, was observed in the optical microscope.

\section{Introduction}

S45C carbon steel is a common engineering steel and widely used for many industrial applications such as machine structures, gears, and parts for actuators or sensors, because of its excellent weldability and machinability. A weld in a steel framed structure sometimes becomes a critical position of failure because of the weak mechanical properties of the welded joint. The mechanical properties of a welded joint are markedly influenced by the thermal cycle of the welding ${ }^{(1,2)}$ and the weld rod. Complex phase transformations caused by the thermal cycle occur during welding and lead to the presence of several microstructures in the weld bead. ${ }^{(3-6)}$ In addition, the performance of the welded joint is greatly affected by the composition of the

\footnotetext{
*Corresponding author: e-mail: chinguo7@yahoo.com.tw

** Corresponding author: e-mail: jhchen@ntnu.edu.tw

http://dx.doi.org/10.18494/SAM.2018.1826
} 
weld rod. ${ }^{(7-9)}$ Therefore, it is essential to clarify the influence of the rod materials on the microstructure and the mechanical properties of welded joints.

This research was aimed at understanding the relation between the microstructure and the tensile properties of a welded joint in S45C carbon steel using four kinds of weld rods. In addition, this study also provided a method to evaluate the suitability of weld rods used in welding the S45C carbon steel.

\section{Materials and Methods}

In this study, we used the multilayer and multipass welding, ${ }^{(10-13)}$ which are widely used methods for the welding of thick plates to investigate the performance of a welded joint. The base metal (BM) was $\mathrm{S} 45 \mathrm{C}$ carbon steel. Its dimensions were $100 \mathrm{~mm}$ in length, $50 \mathrm{~mm}$ in width, and $16 \mathrm{~mm}$ in thickness. To avoid temperature effects on deformation, it was necessary to keep the workpiece cooled with water. Each metal bulk had a bevel of $30^{\circ}$ angle, ${ }^{(14)} 2 \mathrm{~mm}$ depth, and $2 \mathrm{~mm}$ in width. Prior to the experiment, a backing strip, which was a carbon steel plate with dimensions of $100 \mathrm{~mm}$ in length, $25 \mathrm{~mm}$ in width, and $6 \mathrm{~mm}$ in thickness, was welded at the bottom of the BM by spot welding, as shown in Fig. 1.

Before welding, the weld zone of the BM was cleaned using acetone to remove any particles. The experimental process is described in Fig. 2. Four kinds of CNS E4303 carbon steel weld rods, marked A, B, C, and D, were popular in industry and fabricated by different companies. Their individual welding parameters are shown in Table 1. Before welding, residual moisture had to be removed carefully from the weld rod. The procedures were as follows:

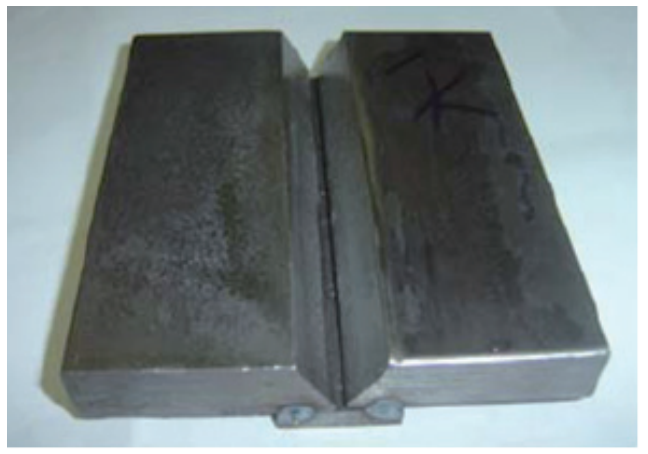

Fig. 1. (Color online) V-butt BM.

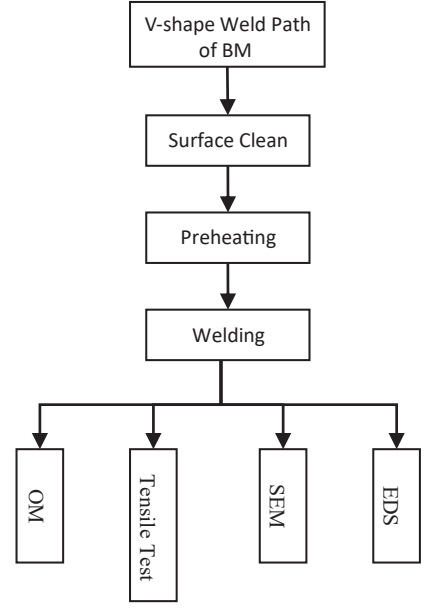

Fig. 2. Flow chart for the experiment.

Table 1

Weld rod parameters.

\begin{tabular}{lcccc}
\hline Weld rod & A & B & C & D \\
\hline Diameter (mm) & 3.2 & 3.2 & 3.2 & 3.2 \\
AC (A) & $100-140$ & $100-130$ & $80-110$ & $80-120$ \\
Actual AC (A) & 130 & 130 & 110 & 120 \\
Method & Flat weld & Flat weld & Flat weld & Flat weld \\
\hline
\end{tabular}


1. Weld rods were kept dry at temperatures from 300 to $500{ }^{\circ} \mathrm{C}$ for $60 \mathrm{~min}$ until welding. Weld rods were stored in a dry container at temperatures from 100 to $150{ }^{\circ} \mathrm{C}$ during welding.

2. To avoid the formation of gas voids, the welding arc must move back and forth.

3. A uniform weave beading, not over three times the diameter of electrode, aids greatly in preventing undercuts in the butt welds.

4. The $\mathrm{BM}$ was preheated at $80{ }^{\circ} \mathrm{C}$ for different times as a function of the thickness of the metal.

5. Four corners of the BM were fixed to avoid distortion.

Multi-layer and multi-pass welding were carried out with the optimum conditions of the rectifier. The interpass temperature must be stable during welding. The weld slag, oxide, and impurity were removed with a brush before next welding. The aim of this study was to analyze the microstructure and mechanical properties of the weld joints. Six zones were selected for the microstructure analysis by optical microscopy (OM), as shown in Fig. 3: (a) BM, (b) hot affect zone (HAZ), (c) fusion line, (d) cover pass, (e) filler pass, and (f) root pass. In addition, according to American Society for Testing and Materials (ASTM) E8M presented in Table 2, all welded steels were machined to be specimens in the tensile test as shown in Fig. 4. After the tensile test, fracture features of specimens were observed by scanning electron microscopy (SEM), and the qualitative analysis of the composition was carried out by energy-dispersive X-ray spectroscopy (EDS).
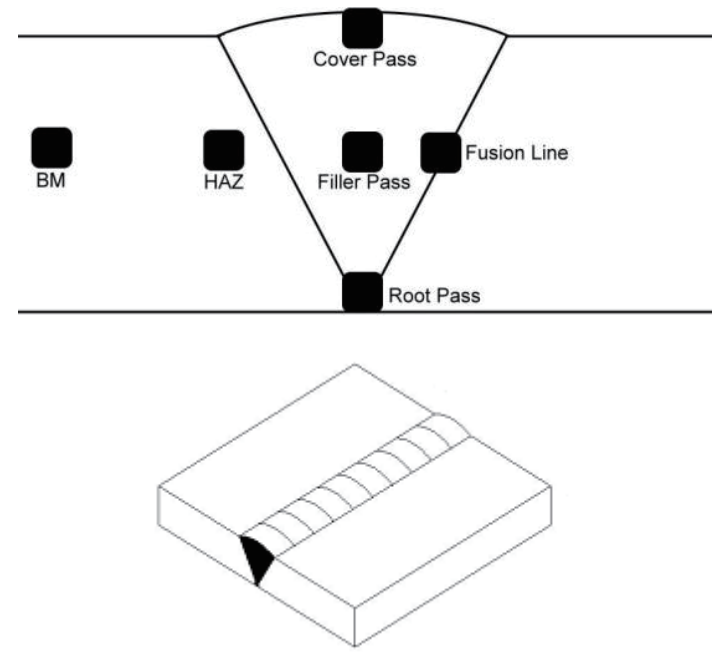

Fig. 3. Selected weld position for microstructure analysis.

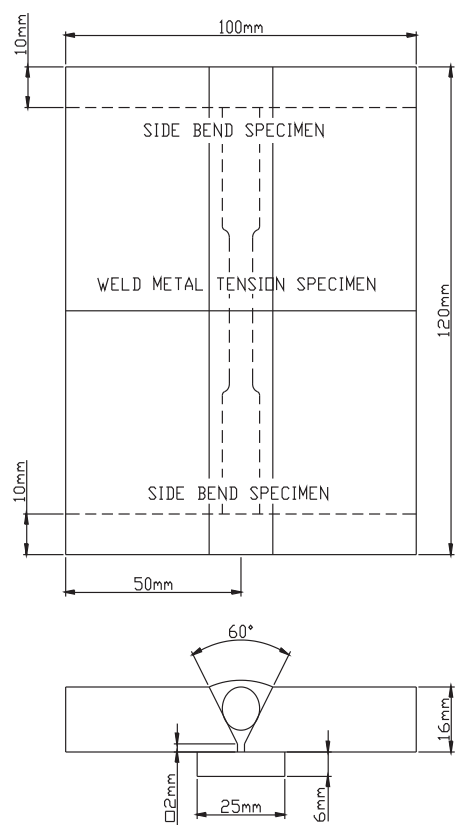

Fig. 4. Sample dimensions for the tensile test.

Table 2

ASTM E8M rule.

\begin{tabular}{cccccc}
\hline \multicolumn{5}{c}{ Standard specimen $(\mathrm{mm})$} \\
\hline$G$ & $62.5 \pm 0.1$ & $45.0 \pm 0.1$ & $30.0 \pm 0.1$ & $20.0 \pm 0.1$ & $12.5 \pm 0.1$ \\
$D$ & $12.5 \pm 0.2$ & $9.0 \pm 0.1$ & $6.0 \pm 0.1$ & $4.0 \pm 0.1$ & $2.5 \pm 0.1$ \\
$R$ & 10 & 8 & 6 & 4 & 2 \\
$A$ & 75 & 54 & 36 & 24 & 20 \\
\hline
\end{tabular}
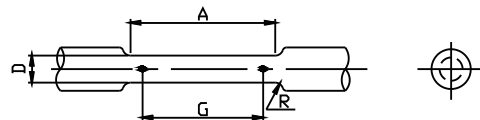

$G$, length; $D$, radius; $R$, minimum radius; $A$, reduction of the minimum length 


\section{Results and Discussion}

\subsection{Microstructure observation}

The compositions of all weld rods are presented in Table 3. The rods marked A, B, and $\mathrm{C}$ were close to typical medium carbon steel. Besides $\mathrm{Fe}$ and $\mathrm{C}$, they contained some minor elements such as $\mathrm{Si}, \mathrm{Mn}, \mathrm{P}$, and $\mathrm{S}$. The compositions of rods $\mathrm{A}, \mathrm{B}$, and $\mathrm{C}$ were similar, but the weight percent of each element varied. The composition of rod D was $27.3 \% \mathrm{Cr}, 0.66 \% \mathrm{Co}$, and 9.17\% Ni in addition to Fe and Si. Rod D was similar to stainless steel, but had better strength than stainless steel 304 and good resistance to corrosion.

The fusion zone was divided into three parts: the cover pass, the filler pass, and the root pass. All compositions and microstructures of the welded rods A, B, and C were similar. After welding, pearlite was present in the filler pass and the root pass. The pearlite in the root pass had a fine structure because the root pass reached a low temperature faster than the filler pass. At the cover pass, more upper bainite microstructure appeared than lower bainite structure. The microstructures of the welds of all specimens are shown in Fig. 5. Dendritic ferrite in the filler pass and the dual phase in the cover pass were also found in significant amount in the specimen D. Because of the presence of $\mathrm{Cr}$ and $\mathrm{Ni}$ in rod $\mathrm{D}$, austenitic-ferritic stainless steel (a mixture of austenite and ferrite) was formed during the thermal cycle.

\subsection{Tensile test}

The specimens for the tensile test were machined according to ASTM standards and made of a full weld bead. Table 4 shows the ultimate strength, the yield strength, the elongation, and the reduction of area (R.A.) of all specimens. The ultimate strength of the specimens A, B, and $\mathrm{C}$ was $460 \mathrm{MPa}$, while those of $\mathrm{BM}$ and specimen D were 664 and $702 \mathrm{MPa}$, respectively. A similar trend was observed in the results of yield strength. The yield stress of the specimens A, B, and $\mathrm{C}$ was about $360 \mathrm{MPa}$. The yield strength of $\mathrm{BM}$ and specimen D were 475 and $486 \mathrm{MPa}$, respectively. All welded specimens showed better elongation and R.A. than those of BM. This indicated that the ductility of the welded specimens was enhanced by the thermal cycle during welding. However, improvements in the yield strength and the ultimate strength were only observed in specimen D.

Table 3

EDS analysis results.

\begin{tabular}{lcllccc}
\hline Specimen & Fe & C & $\begin{array}{c}\text { Si } \\
\text { (wt.\%) }\end{array}$ & Mn & S \\
\hline A & 99.11 & 0.42 & 0.08 & 0.29 & 0.05 & 0.05 \\
B & 98.63 & 0.5 & 0.25 & 0.53 & 0.04 & 0.05 \\
C & 98.99 & 0.55 & 0.21 & 0.17 & 0.03 & 0.05 \\
D & 60.98 & 0.01 & 1.39 & 0.49 & 27.3 & 0.66 \\
BM & 98.59 & 0.48 & 0.3 & 0.57 & 0.02 & 0.04 \\
\hline
\end{tabular}




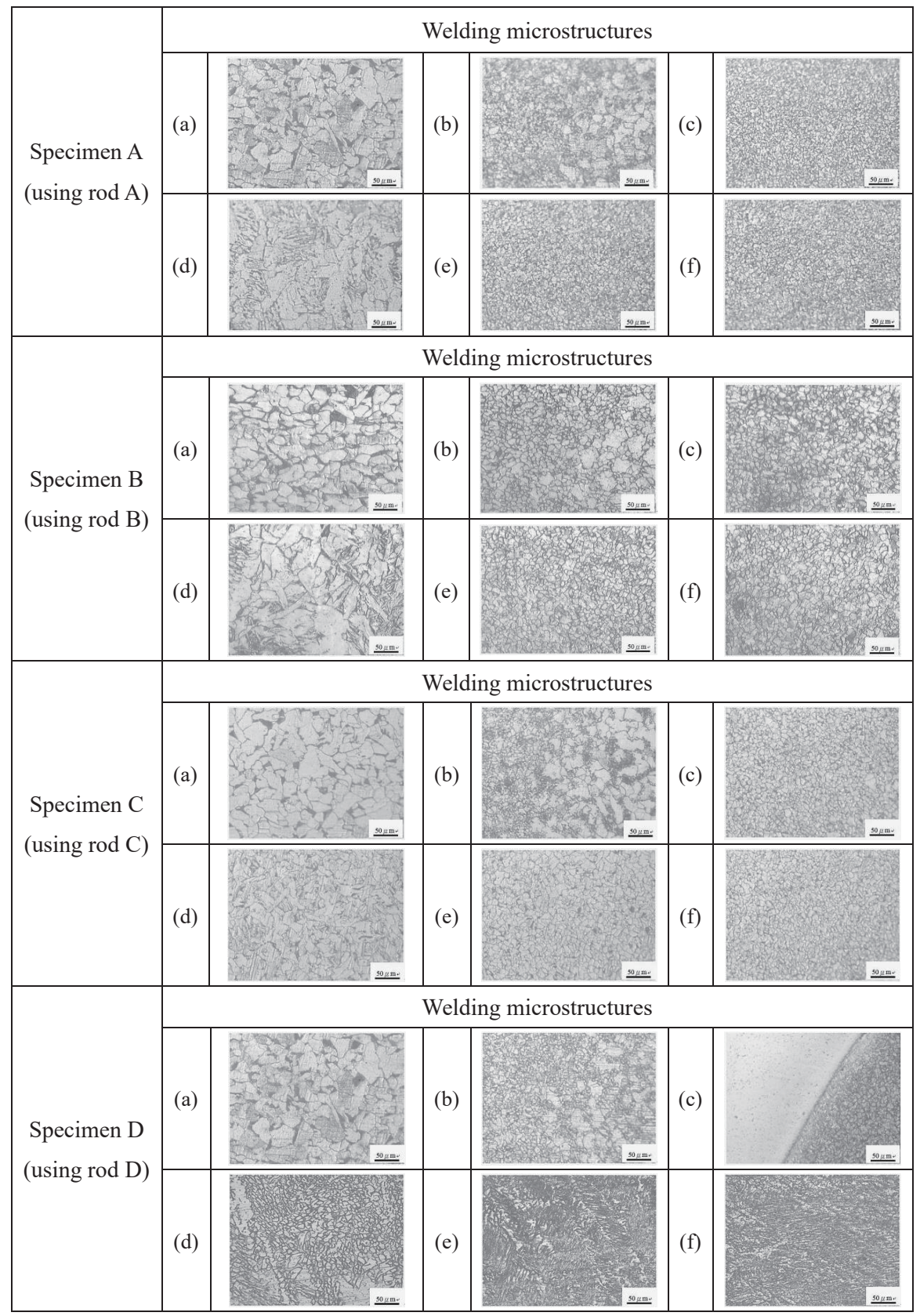

Fig. 5. Welding microstructures of the specimens A, B, C, and D examined by OM: (a) BM, (b) HAZ, (c) fusion line, (d) cover pass, (e) filler pass, and (f) root pass.

Table 4

Tensile test data.

\begin{tabular}{lcccc}
\hline Specimen & $\begin{array}{c}\text { Average elongation } \\
(\%)\end{array}$ & $\begin{array}{c}\text { Average yield strength } \\
(\mathrm{MPa})\end{array}$ & $\begin{array}{c}\text { Average ultimate strength } \\
(\mathrm{MPa})\end{array}$ & $\begin{array}{c}\text { Average R.A. } \\
(\%)\end{array}$ \\
\hline A & 36 & 367 & 456 & 63 \\
B & 30 & 359 & 477 & 68 \\
C & 36 & 358 & 460 & 66 \\
D & 41 & 486 & 702 & 68 \\
BM & 18 & 475 & 664 & 53 \\
\hline
\end{tabular}




\subsection{Fracture analysis}

Different from the fracture behavior of BM, all welded specimens displayed ductile fracture with dimples, as shown in Fig. 6. Some carbide-like particles were observed inside the dimples. While the thermal cycle of the welding induced complex phase transformation, the ductility of the welded specimen was affected by the composition and distribution of carbide-like particles which formed in the repeated heat treatment during welding. In the beginning of the tensile test, the initial dimpling was produced due to the high stress field caused by numerous dislocations which were concentrated near the hard particles. Microvoids appeared in the interface between the hard particles and the matrix. The voids were elongated by the tensile stress and connected laterally to each other by the internal stress. Finally, microcracks formed and many dimples were observed on the ductile fracture surface. In Fig. 6(d), specimen D had the finest dimple structure in the fracture surface. The fracture behavior was consistent with the mechanical properties determined by the tensile test.

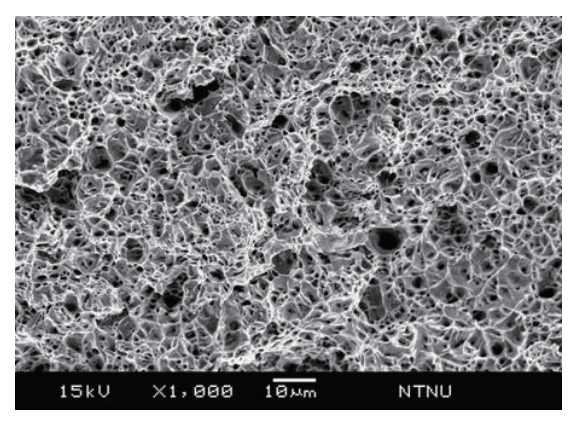

(a)

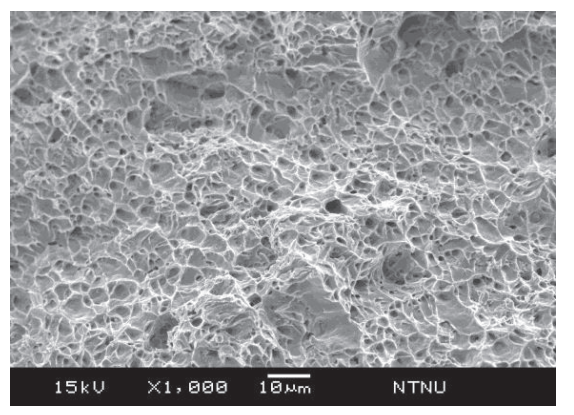

(c)

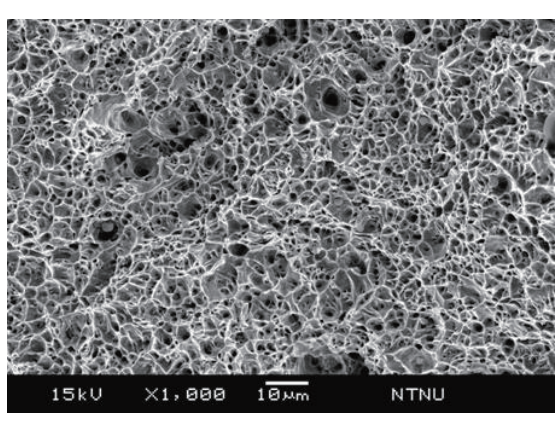

(b)

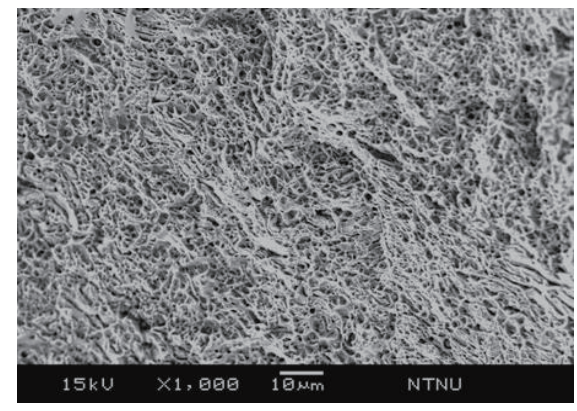

(d)

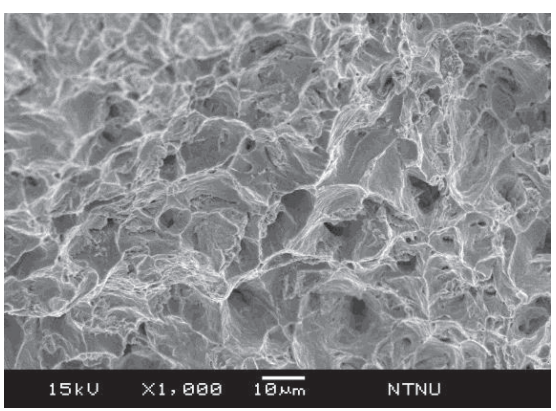

(e)

Fig. 6. Fracture morphologies examined by SEM: (a) specimen A, (b) specimen B, (c) specimen C, (d) specimen D, and (e) BM. 


\section{Conclusions}

The composition of rod D was close to that of stainless steel. After welding to BM, austenitic-ferritic stainless steel (dual phase stainless steel) was observed in the cover pass. The compositions of the other three weld rods were close to that of medium carbon steel. Observation of the microstructure showed that pearlite and bainite existed from the root pass to the cover pass. The results of tensile tests revealed that the yield strength of specimen D increased 35\% over that of the other three rods. Meanwhile, the ultimate strength of specimen $\mathrm{D}$ also showed an increase of $65 \%$ over that of the other three rods. Fracture analysis indicated that all specimens had ductile failure. A fine dimple structure was observed in specimen D and contributed to better ductile properties in tensile tests. This study provided a method to evaluate the suitability of weld rods when welding S45C carbon steel.

\section{Acknowledgments}

The authors are grateful for the support of the Taiwan Foundry Society (Grant No. 105K0100).

\section{Conflicts of Interest}

The authors declare no conflict of interest.

\section{References}

1 S. Murugan, D. K. Rai, P. V. Kumar, T. Jayakumar, B. Raj, and M. S. C. Bose: Int. J. Pressure Vessels Piping 78 (2001) 307.

2 Y. Ueda, E. Takahashi, K. Fukuda, and K. Nakacho: Trans. JWRI 3 (1974) 59.

3 M. Sahin: J. Mater. Process Technol. 168 (2005) 202.

4 A. P. Reynolds, W. Tang, T. Gnaupel-Herold, and H. Prask: Scripta Mater. 48 (2003) 1289.

5 D. J. Lee, J. C. Byun, J. H. Sung, and H. W. Lee: Mater. Sci. Eng. A 513 (2009) 154.

6 A. Celik and A. Alsaran: Mater. Charact. 43 (1999) 311.

7 R. H. Koztowski: J. Mater. Process Technol. 53 (1995) 239.

8 H. Fujii, L. Cui, N. Tsuji, M. Maeda, K. Nakata, and K. Nogi: Mater. Sci. Eng. A 429 (2006) 50.

9 L. Cui, H. Fujii, N. Tsuji, and K. Nogi: Scripta Mater. 56 (2007) 637.

10 K. Ogawa, H. Yamaguchi, S. Kaga, and K. Sakaguchi: Trans. Jpn. Weld. Soc. 24 (1993) 47.

11 R. Kacar and O. Baylan: Mater. Des. 25 (2004) 317.

12 S. D. Meshram, T. Mohandas, and G. M. Reddy: J. Mater. Process Technol. 184 (2007) 330.

13 A. Ozekcin, H. W. Jin, J. Y. Koo, N. V. Bangaru, R. Ayer, G. Vaughn, R. Steel, and S. Packer: Int. J. Offshore Polar Eng. 14 (2004) 105.

14 P. Wongpanya: J. Met. Mater. Miner. 19 (2009) 67. 